\title{
User Experience Technique in Computer Digital Arts Production: Paper Prototyping Used as Material to Define Intentionality
}

\author{
Marília Lyra Bergamo ${ }^{1,2}$ \\ ${ }^{1}$ University of Brasília, Brasília, Brazil \\ ${ }^{2}$ Federal University of Minas Gerais, Belo Horizonte, Brazil, supported by FAPEMIG \\ (Minas Gerais State Foundation for Research Support) \\ marilialb@eba.ufmg.br
}

\begin{abstract}
This papers aims to describe the historical introduction of paper prototyping techniques into interface development, what they basically consist of, and how such techniques can be applied on the development of Computer Digital Arts. With some examples applied on Digital Arts graduation courses at the Federal University of Minas Gerais in Brazil, this technique has proven to help the development of the artist's intentionality, rather than blocking creativity. It helped students to focus on important concepts that needed to be transmitted by interaction, while usability made the piece friendly where it needed to be friendly. Thus, young art students have been acting in a traditional way when experimenting with materials, not only physically and visually, but also with the interactive environment that should be considered as material in Computer Digital Arts.
\end{abstract}

Keywords: Mental Model Design, Usability Methods and Tools, Computer Digital Arts.

\section{Introduction}

The postmodern word interface is as common as its function. A few years ago, still between the 1970s and 80s, the discourse about the human-machine interface was fundamentally scientific, and technological domain of the exact sciences. Over the years, as ubiquitous computing became real, interface ceased to be a term associated only with the field of technology, and became a part of the discourse of the social sciences. It is only natural, since interface means mediation and, as such, communication. However, in this process, interface between man and machine has not lost its technological nature; it was born in the context of computer use, that is, a state machine. Thus, interface is historically the development of man's relationship with computational processing information.

For this reason, some interface development features are culturally intrinsic to every field that uses computation and human-machine interaction. This should also be true when Computer Digital Art is produced. But, because some discourses in Art are 
so eager to defend the importance of flaws in creative processes, the idea of using techniques that are related to usability found an inhospitable environment at traditional fine art schools. This is, sometimes, unfortunately a reality.

However, creative schools with focus on design usually do not have the same problem and user experience techniques such as paper prototyping with interfaces has gained importance with the introduction of new students. Due to their familiarity with industrial production and concept development, some kind of prototyping should naturally be used when developing interfaces. In specific, paper prototyping has become a very important tool, because it allows the development of the design concept with potential to usability tests. As a result, user experience techniques with paper prototyping are fully accepted in design, as well as in other creativity areas. Nevertheless, it still seems to be left out of most Computer Digital Arts methodology. Art practices are usually very experimental as regards the materials used, and the results achieved are somehow incorporated into the final piece. This is true when it comes to Computer Digital Arts,. However, it does not mean that intentionality related to functionality available on the piece does not need testing.

The Federal University of Minas Gerais presents a different reality. Some Digital Art students practice user experience techniques in the early years of their education. Paper prototyping, in special, has provided art students with the best practical approach to experimenting with interaction, the same way they already do when dealing with visual and physical materials. Such students are motivated to think of interaction both as sketching and as materialized practice. This paper will present the historical approach to those techniques on design literature, as well as paper prototypes produced by students.

\section{Historical Introduction on the Relationship between Design, Art, and User Experience Techniques}

The early years of the development of computer interfaces are marked by the adoption of interface as translation among media. Consequently, we watched the development of models that related men and machines focusing on textual cognitive models. According to Johnson [4] and Moggridge [7], with the development of the mouse device, direct manipulation in two-dimensional space created by computational procedures became possible. This was a very important step towards the development of interfaces. With direct manipulation came the metaphor for the transposition of the visual analog world to computer interaction. Interfaces then became graphic, and part of the cognitive visible world. This characteristic brought visual fields of knowledge and the development of interfaces closer together, since the same basic principles that govern visual arts have also been explored in human-machine interaction.

Among the various professionals who were involved in this area, graphic designers were by nature qualified professionals for this type of development. Graphic designers work with visual art principles in order to produce communication pieces, and therefore began to understand interface as a new working field, often in partnership with professional computer programming. According to Moggridge [7], 
the duo Tim Mott and Larry Tesler is a good example of these partnerships. Tim Mott was challenged by the idea of working out the new publishing system for Xerox Corporate, which he considered completely unusable for others than the people who built it. They worked together building the still used metaphor of an office desktop: all computer files were transformed into documents that could be carried and dropped onto a printer or into a trashcan.

The beginning of this century saw the emergence of some pieces of artwork created by computer processing that involved not only direct manipulation or input textual data [1]. Of course this did not occurred in isolation. As an example, the field of automation carried out studies that involved theoretical and practical concepts of two different disciplines: computing and electronics. The result of this combination may be seen in art works such as those of artist Daniel Rozin [3] and his mirrors. The image captured by the camera and processed by the computer is transformed into physical behaviors through electronics. His mirrors are physical representations of the pixel; these units behave as the smallest visible units of the piece, and translate the camera view into units that are both virtual and physical.

As a result of this, some contemporaneous interfaces are treated as tangible, and presuppose the existence of physical devices capable of communicating with the computer. Besides the interface sensible capacity (sensors and actuators), computational processing is now incorporating cognitive intelligence, making this medium increasingly complex. Interfaces are coupled with artificial intelligence and mechanisms of perception of human behavior. It can also recognize user actions and information processing input. Joining the recent technological developments in the area of mobile telephony, the coupling of gestures in two-dimensional interactive spaces, and motion capture techniques, the development of interfaces has become essentially multidisciplinary, a kind of space where several professionals work differently although with equivalent levels of importance. Among these, product designers found a fertile working ground, due to the fact that commercial product design now incorporates computational procedures. Daniel Rozin [3], for example, was trained as an industrial designer, and his work uses customized software.

\section{User Experience Techniques Used in Computer Digital Art Development}

The Federal University of Minas Gerais Animation and Digital Arts Graduation Program offers disciplines in both areas, but most of the students are more interested in animation. Young art students are very reluctant to study digital art. The origin of this reluctance towards the digital art field is coding and programming. Although being a part of the School of Fine Arts program, some of the initial disciplines concerning these topics are given at the College of Computer Science. Difficulty in learning coding is a reaction to the inability to understand the foundations of digital technology. Curiously art students are excellent at digital drawing, and very proactive to experiment with digital graphic tools. Nevertheless, as regards how and what these tools are built for, they have no interest. 
Coding is a frustrating activity if done repeatedly due to lack of planning. Moreover, it may be even harder to recode when users do not know how to use the interface, and as a result of this, not only codes but the entire piece need to be rebuilt. This is an old lesson for the computer industry, for which specific commercial goals are essential. However, art students have no such goals to achieve, but simply intentions. While coding mistakes may be interesting to digital animation, this is not true when it comes to interaction. In Computer Digital Art, codes are finishing settings of a previous material, the interaction itself, and through user experience techniques art students can experiment with this interaction. Tools such as personas, use-case diagrams, scenarios and paper prototyping are introduced to design students in their first or second semester, but art students do not have access to this information on their course's curriculum. As result of this, teaching interface design to art students has been a laboratory of user design techniques.

The first technique introduced to art students is conceptual modelling. Rather than writing, art students are encouraged to draw, and are constantly motivated to specifically draw how the interaction piece would work. On this phase, it is important to think about the physical and graphic information, and draw sequences of how people would be interacting with it. Buxton's book, Sketching User Experience [2], is particularly applied to create conceptual models as it presents drawing as an essential tool to think about interaction. One interesting point is that when art students finish sketching conceptual models, they immediately want to start coding. After thinking about interaction through drawing, coding suddenly turns into something interesting.

Good exploratory sketches can help art students to discover their intentions, but not to understand their target audience. Thus it is important to motivate students to create personas, use-case diagrams, scenarios, flowcharts and navigation maps in order to understand how users would act through interactive digital art pieces. Although this is an important part of the process of mapping user experience, art students are unmotivated to do it. No important improvement in discovering the effectiveness of intention has been observed in art students while using those tools. Specially scenarios are less helpful to the process. On the other hand, when art students are asked to transpose interaction onto paper, and create art pieces that pretend to be working in computing environments, motivation can be again observed. Art students take time creating and recreating their interfaces with paper; it makes them think as product and graphic designers. They found it easier to make changes directly on paper prototype than rewriting something on the scenarios. This attitude is not equal to usecase diagrams and flowcharts, and art students found them very useful when preparing their prototypes.

Art students are asked to prepare paper prototypes to perform between two or three tasks that are fundamental to their intentions. Those prototypes are tested with volunteer users. That consequently leads to another two sections of paper prototyping redesign, in which art students have to go back to their activities of discovering what can be improved in order to better apprehend their intentions towards the audience. User tests show art students the wide range of reactions people may have while dealing with interfaces, and this is the specific material they need to experiment with before carrying out any coding or exhibition in Computer Digital Art. 


\section{$4 \quad$ Student's Work Examples}

This section presents four selected works of art students that were produced according to the description in the last section. All of them had conceptual models, user experience documentation and paper prototypes, and were selected along the years of 2012 and 2013. These projects have gone through two or three different versions of paper prototyping since its conceptual modelling and documentation, and all usability problems and versions will be presented in result tables.

\subsection{Share a Smile Application}

This project was produced by student Débora Mini Almeida in 2012. The application basically consisted of sharing smiles around the world. The student has defined the piece intentions as something like: sharing smiles as a way to make people happier.
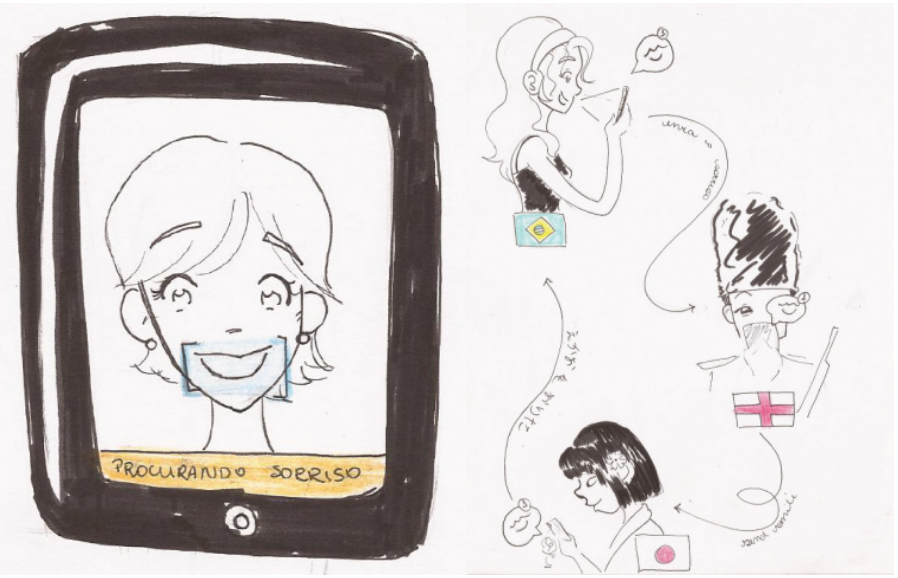

Fig. 1. Share a Smile Application Conceptual Model, drawing by Débora Mini Almeida, 2012. This image was modified. Textual note descriptions in Portuguese were eliminated in this paper presentation.

Table 1. Table of results from usability tests on paper prototyping, Share a Smile Application

\begin{tabular}{llll}
\hline Problem & $\begin{array}{l}\text { Prototype } \\
\text { Version }\end{array}$ & Priority & Solution found \\
\hline Excess of information to sign in. & 1 & Medium & $\begin{array}{l}\text { Sign in form with e-mail address } \\
\text { and agreement only. }\end{array}$ \\
\hline $\begin{array}{l}\text { While reading email, application } \\
\text { was interrupted, and users were } \\
\text { unable to return the smile }\end{array}$ & High & $\begin{array}{l}\text { The student wants to make } \\
\text { people happy with smiles, but } \\
\text { interrupting users did not work. } \\
\text { A waiting icon was placed on } \\
\text { the top the device. }\end{array}$ \\
$\begin{array}{l}\text { Users were annoyed for not } \\
\text { knowing where the smile came from }\end{array}$ & $\begin{array}{l}\text { A flag was placed together with } \\
\text { the smile picture }\end{array}$ \\
$\begin{array}{l}\text { Users could not identify where the } \\
\text { flag was from }\end{array}$ & Medium & $\begin{array}{l}\text { Flags were replaced by names of } \\
\text { countries }\end{array}$ \\
\hline
\end{tabular}




\subsection{Artificial Stars Installation}

Created by Isadora Morales in 2012, Artificial Stars Installation was inspired by a Chinese comic book called Knite. Set in a Chinese metropolis, the book presents a character who is part of a group frustrated by the impossibility of seeing stars in the night sky of the city. They then decide to create artificial stars. In the comic book these stars are cloth kites with small lamps. The conceptual model is an installation of gas balloons with wires and lights. Balloons could be controlled by a mobile device application, which enabled them to physically follow the user's geographic position value within a predetermined perimeter of the installation. The installation paper prototype was mainly focused on: 1 . How users would react to the application; 2 . How users would be coordinated by the application; and 3. How the application would let users know if they were followed by any balloon. For the user tests, a black gas balloon with Christmas lights tied to a string was used.

Table 2. Table of results from usability tests on paper prototyping, Artificial Stars Installation

\begin{tabular}{llll}
\hline Problem & $\begin{array}{l}\text { Prototype } \\
\text { Version }\end{array}$ & Priority & Solution found \\
\hline $\begin{array}{l}\text { Users were annoyed for having } \\
\text { to sign in to be followed }\end{array}$ & High & $\begin{array}{l}\text { No personal identification was } \\
\text { needed to enter the software, only } \\
\text { the geographic position and an ID } \\
\text { should be generated, without the } \\
\text { user's knowledge, to queue users. }\end{array}$ \\
\hline $\begin{array}{l}\text { Users could not identify which } \\
\text { balloon was attached to them. }\end{array}$ & High & $\begin{array}{l}\text { A feedback color tag was placed } \\
\text { on each balloon. }\end{array}$ \\
\hline $\begin{array}{l}\text { Users did not manage to } 2 \\
\text { identify which color tag was } \\
\text { attached and again did not } \\
\text { identify which balloon was } \\
\text { attached to them. }\end{array}$ & High & $\begin{array}{l}\text { A map of all balloons was created } \\
\text { as a feedback for users, and the } \\
\text { one that followed the specific } \\
\text { user was highlighted. }\end{array}$ \\
\hline
\end{tabular}

\subsection{Interactive Mirrors Installation}

Projected by Matheus Guedes de Paula in 2012, the interactive mirrors would be screens coupled with cameras simulating mirrors, to be placed in public bathrooms, and changing rooms at clothing shops. The screens would show a virtual person interacting with the audience, asking questions, playing games, and so on. His prototype was more a performance test, and an actor was hired to follow a specific script simulating the artificial intelligent software intended. 


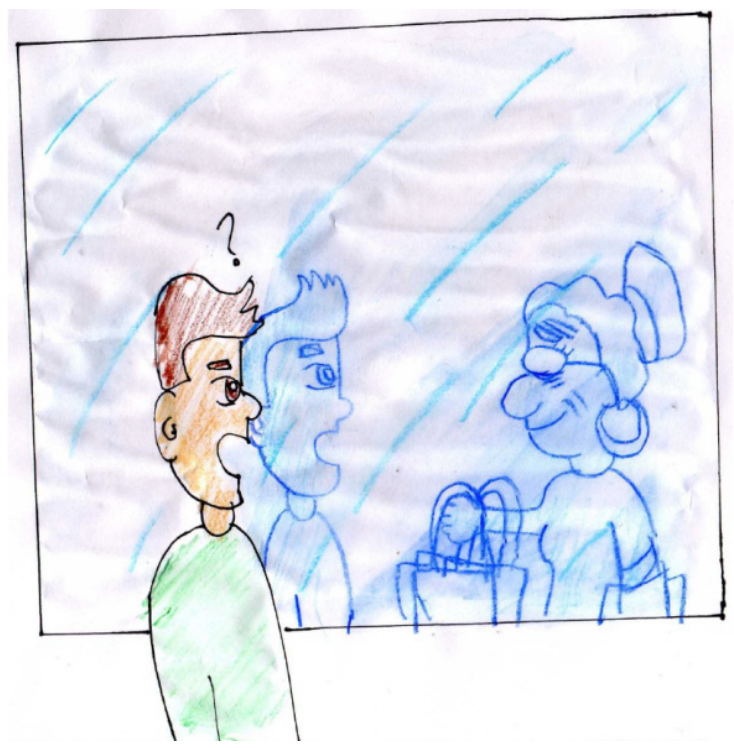

Fig. 2. Conceptual Model of Interactive Mirrors Installation. This image was modified. Textual note descriptions in Portuguese were eliminated in this paper presentation.

Table 3. Table of results from usability tests on paper prototyping, Interactive Mirrors Installation

\begin{tabular}{llll}
\hline Problem & $\begin{array}{l}\text { Prototype } \\
\text { Version }\end{array}$ & Priority & Solution found \\
\hline $\begin{array}{l}\text { Users kept looking at the } 1 \\
\text { actor on their backs }\end{array}$ & low & $\begin{array}{l}\text { A real time projection was } \\
\text { screened on a white paper } \\
\text { attached to the mirror. }\end{array}$ \\
\hline $\begin{array}{l}\text { Users kept touching the } 1 \\
\text { real projection }\end{array}$ & Medium & $\begin{array}{l}\text { Reactions to touch actions were } \\
\text { inserted in the script, depending } \\
\text { on where the touch happened. }\end{array}$ \\
\hline
\end{tabular}

\subsection{Virtual Graffiti Installation}

A project by Diego Falabella, Geisa Souza, Jessica Hissa, João Marcos, Lídia Soares, Saulo Ishutani and Teiciany Sena, 2013. Inspired by street art and its intense criticism against graffiti expression, the work intends to bring together the audience and reflections about the theme. The interface protopype is a spray can interface that helped the audience to produce virtual images in graffiti. 


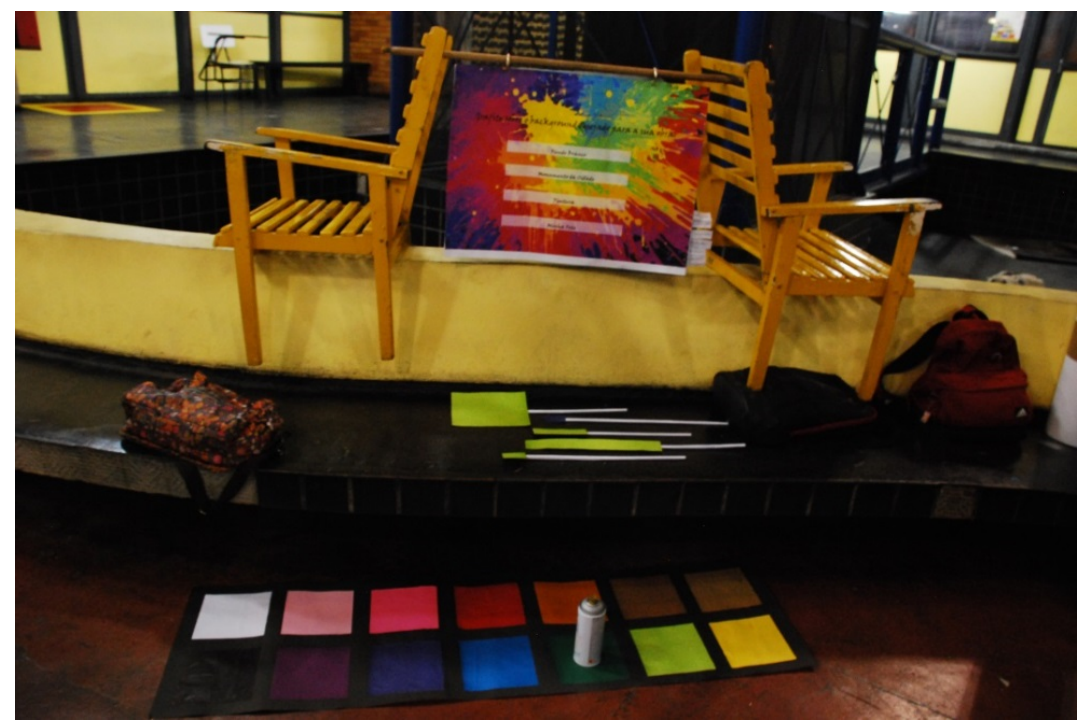

Fig. 3. Virtual Graffiti Installation. Paper prototyping installation in 2013, photographed by Marilia Bergamo

Table 4. Table of results from usability tests on paper prototyping, Virtual Graffiti Installation

\begin{tabular}{llll}
\hline Problem & $\begin{array}{l}\text { Prototype } \\
\text { Version }\end{array}$ & Priority & Solution found \\
\hline $\begin{array}{l}\text { Users had questions on how to } \\
\text { save the screen }\end{array}$ & Medium & $\begin{array}{l}\text { Change position of saving } \\
\text { icon }\end{array}$ \\
$\begin{array}{l}\text { Users do not understand how to } \\
\text { scrabble, paint or interact with the } \\
\text { screen. }\end{array}$ & High & $\begin{array}{l}\text { The spray can interface was } \\
\text { redesigned; some buttons } \\
\text { were eliminated and placed } \\
\text { on the screen, where users } \\
\text { were more focused. A color } \\
\text { panel was placed on the } \\
\text { floor. }\end{array}$ \\
& & $\begin{array}{l}\text { A restart button was included } \\
\text { on the spray can interface. }\end{array}$ \\
\hline $\begin{array}{l}\text { User cannot restart the installation } \\
\text { after finishing drawing }\end{array}$ & 2 & High & $\begin{array}{l}\text { Colors are now chosen by } \\
\text { being stepped on }\end{array}$ \\
\hline Color panel was stepped on & 2 & Medium & \\
\hline
\end{tabular}

\section{Conclusions}

The experience of teaching user-centered methodology with art students has led to three important conclusions about this process in this specific environment. First of all, this methodology has been applied to the earliest moment of the creation process. For this reason, it is important that some flexibility can be applied, especially, to the documentation. Documentation is important, but art students draw more out of pleasure, which means that some documentation can be conceived in sketching, and this sketching should be considered as an early stage of the user-centered process in art environments. 
This conclusion leads to a second one, that some usability principles, such as feedback, restrictions and consistency should be incorporated into the minds of art students during the entire sketching process. In other words, because those creations are usually not very related to previously existing solutions, usability heuristic recommendations are, sometimes, of little use. As a result, if the principles are understood and accepted beforehand by those students, their drawings and sketches tend to be created incorporating usability right from the very start of the creation process.

At last, the third conclusion is about the prototyping methodology. Paper prototyping in digital art should be an amplified concept of low fidelity prototyping. Paper can be used, but all other kinds of cheap materials have been used, such as balloons and broomsticks. For this reason, any low fidelity, which won't cost the students too much money or time to develop, becomes material to experiment with interaction itself. Also this prototyping methodology in digital interaction art has demonstrated that the environment where the tests take place plays an important role in the process of acquiring user information. Sometimes performances are necessary, like in the Interactive Mirrors Installation, and at other times, the dark outdoor environment was fundamental, like in the Artificial Stars Project. This means, once again, another level of flexibility in the process of user testing. Classrooms, for example, do not suit as a good unbiased place for testing. On the contrary, the environment becomes part of the prototype itself.

In conclusion, with these prototypes and sketches, and more flexible methodology incorporated into usability principles, art students have demonstrated a better apprehension of user-centered concepts, and have observed the importance of such concepts for the audience, which consequently leads to acquiring clearer intentions.

\section{References}

1. Bolter, J.D., Gromala, D.: Windows and mirrors: interaction design, digital art, and the myth of transparency. MIT Press, Cambridge (2003)

2. Buxton, B.: Sketching User Experiences: Getting the Design Right and the Right Design. Morgan Kaufmann (2007)

3. Danil Rozin Interactive Art (2014), http: / /www. smoothware.com/danny/ (retrieved January 21, 2014)

4. Johnson, S.: Interface Culture: How New Technology Transforms the Way We Create and Communicate. Harper Collins Publishers Inc., New York (1997)

5. Jordan, P.W.: Designing pleasurable products: an introduction to the new human factors. Taylor \& Francis, London (2000)

6. Laurel, B., Mountford, S.J.: The Art of human-computer interface design. Addison-Wesley, Reading (1990)

7. Moggridge, B.: Designing interactions. MIT Press, Cambridge (2007)

8. Norman, D.A.: The design of everyday things, 1st Doubleday/Currency edn. Doubleday, New York (1990)

9. Snyder, C.: Paper Prototyping: The Fast and Easy Way to Design and Refine User Interfaces. Elsevier, San Francisco (2003) 